\title{
Filter design impacton drainpipe water intake capacity
}

\author{
Ol'ga Zaborskaya ${ }^{1}$, Andrey Nikitin ${ }^{1, *}$, and Alexander Nevzorov ${ }^{1}$ \\ ${ }^{1}$ Northern Federal University named after M.V. Lomonosov (NArFU), Severnaya Dvina Emb., 17, \\ Arkhangelsk, 163002, Russia
}

\begin{abstract}
The city of Arkhangelsk is located on a marshy plain, where the groundwater level used to coincide with the surface. The area preparation for construction consisted in filling a layer of sand over peat. Hence, the following characteristic geotechnical conditions of the newly developed areas: high groundwater level and long-term settlement of peat under sand embankment. That is why subsurface structures are protected by a drainage, and drains are installed over pile foundations. One problem developing in the course of drain operation and requiring expensive reinstallation activities is clogging of drain filters with fine organic and clay particles carried over by groundwater flow. The article presents the results of a survey of a building erected more than 30 years ago, which suffered from groundwater table rising due to the reduction of drain system's water intake capacity. Clogging of crushed stone cover above the drainpipe resulted in the reduction of the permeability factor. Laboratory surveys were conducted to estimate the reliability of drains with the pipes wrapped in geotextile. Drains with a layer of geotextile surrounding the stone filtering cover were also investigated. To simulate clogging, humus and clay particles were added to the water running through the filtering tube. It turned out that the second geotextile arrangement - around the stone cover with sand backfillingwas the most effective.
\end{abstract}

\section{Introduction and background}

The city of Arkhangelsk is located on lowland marshy shores and islands in the delta of the Northern Dvina River, where the original peat deposit thickness reached several meters. Area preparation for construction includes filling a 2 to $4 \mathrm{~m}$ thick layer of sand onto the marsh surface. Hence, the following characteristic geotechnical conditions of the newly developed areas: high groundwater level and long-term settlement of peat under the sand embankment.

The operating experience of underground pipelines in the 1960s has shown that such utilities became inoperable within the first years after installation due to uneven settlement of peat. Therefore, starting with the 1970 s, all pipelines were laid over pile foundations where peat was present[1,2]. In particular, drainpipes were built on both wooden and

\footnotetext{
* Corresponding author: nikitinavsafu@yandex.ru
} 
concrete driven piles. Wooden piles were spaced at 1.5 to $2.5 \mathrm{~m}$, and concrete piles - at 3 to $4 \mathrm{~m}$.

The drainage is generally made of perforated pipes 150 to $300 \mathrm{~mm}$ in diameter with crushed stone or gravel covers. Vertical wooden panels ensure the stability of stone covers under the influence of surrounding soil movement due to underlying peat settlement.

Recently, a wide-scale problem of drains becoming inoperable was discovered due to active utilization of basement floors. As an example, the first part of article provides the survey results for a shopping centre.

As compared to the 1970 s, the drain design in the city has not undergone any significant changes. The only difference is that drains are protected with geotextile to prevent silt contamination [3-15]. Mostly geotextile is used as a wrap of drain pipes and occasionally it is laid along the external outline of the stone or gravel cover[3,4,11,12]. The reliability of geotextile filters was evaluated with the laboratory experiments. Their results are presented at the second part of article.

\section{Field investigation}

The shopping centre was built in 1986. It is a two-storey building, frame-type, on a pile foundation, with basement depth $2.3 \mathrm{~m}$ from the surface. The peat layer thickness under the building is $0.9 \mathrm{~m}$, sand $-1 \mathrm{~m}$.Outside the building, the peat layer is $2.9 \mathrm{~m}$ thick, sand -1.5 $\mathrm{m}$.Very soft clay underlies the peat layer. The investigation included pit digging, examination of wells, soil sampling and laboratory testing.

There is a drainpipe around the building installed on a foundation of paired piles $6 \mathrm{~m}$ long and reinforced concrete beams(Figure 1). Drainpipes are asbestos-cement, $150 \mathrm{~mm}$ in diameter, with a crushed stone cover with grain size 40 to $100 \mathrm{~mm}$. The pipe bottom is at the depth of 2.80 to $3.70 \mathrm{~m}$ from the surface and at the distance of $3 \mathrm{~m}$ from the building. The drain backfilling material is fine sand with clay and peat inclusions. Due to groundwater rising in $1990 \mathrm{~s}$, a well with $1.5 \times 1.5 \mathrm{~m}$ cross section was excavated under the building; water was pumped out of the well continuously.

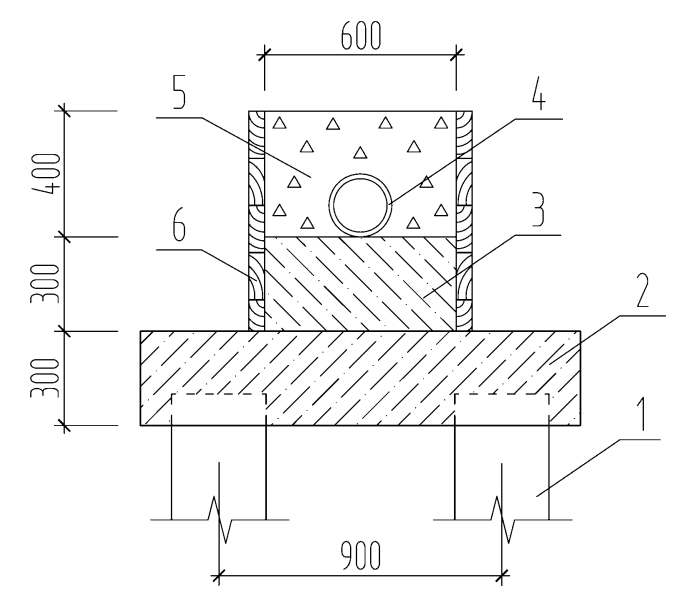

Fig. 1.Drain design: 1 - pile $300 \times 300 \mathrm{~mm}, 2$ - grillage, 3 - reinforced concrete beam, 4 - drainpipe, 5 stone cover, 6 - board wooden panels.

Pit survey has shown that the space between the crushed stone grains was packed with sand and clayey particles. The material composition and water permeability were determined by testing of samples: No. 1, 2 - stone cover, No. 3 - 6 - back filling at the distance of 0.5 and $2 \mathrm{~m}$ from the drain(Figure 2). 


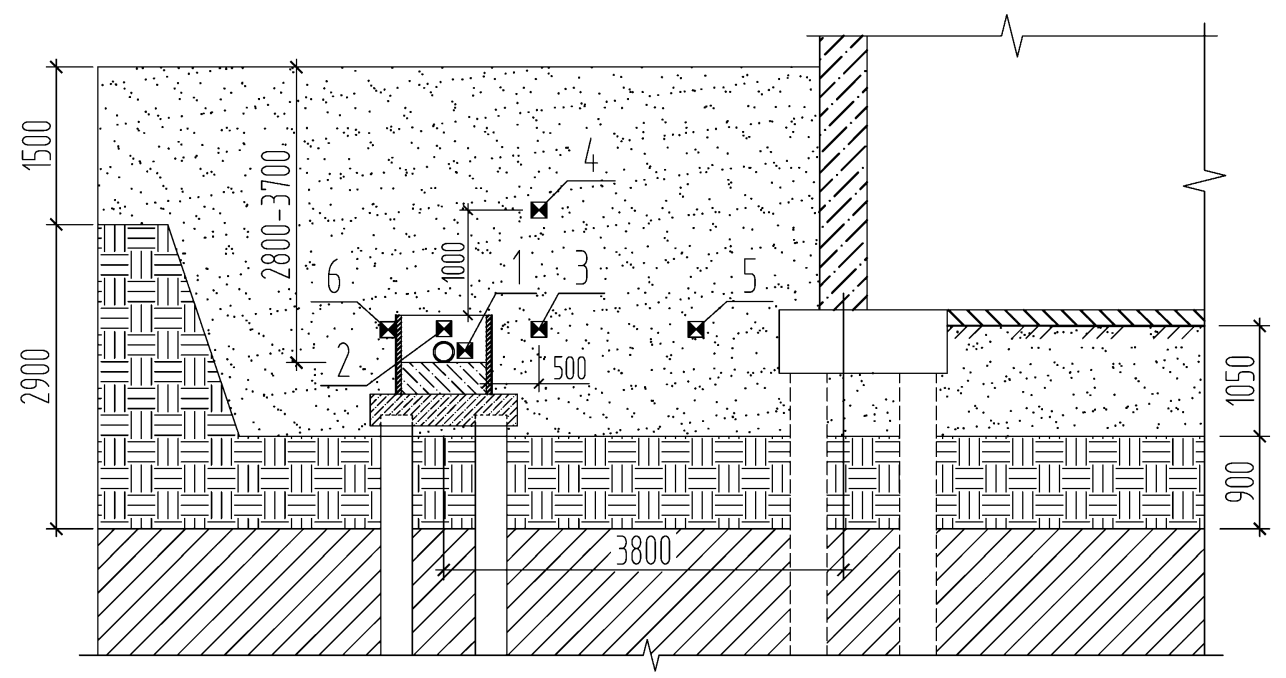

Fig. 2. Drainage system layout with sampling points.

The average grain-size composition of the material filling the space between crushed stone particles and the backfilling soil is shown in Figure 3.

It should be noted that the quantity of particles less than $0.1 \mathrm{~mm}$ in the stone cover is 2 to 3 times greater than their quantity in the backfilling sand, which indicates that these particles were carried over by the groundwater flow and clogged the filter. The quantity of organic matter in the stone cover is also 2 to 2.5 times greater than in the backfilling.

Drainage well examination showed that the drainpipes are filled with small soil particles and organics by 20 to $40 \%$ of the cross section. This is usually called "silt contamination of drains". The content of particles less than $0.1 \mathrm{~mm}$ in the drainpipe plugs varies from 18.9 to $41.0 \%$ by weight with the average value $28.2 \%$; the content of organics varies from 6.1 to $12.9 \%$ (average value $8.4 \%$ ).

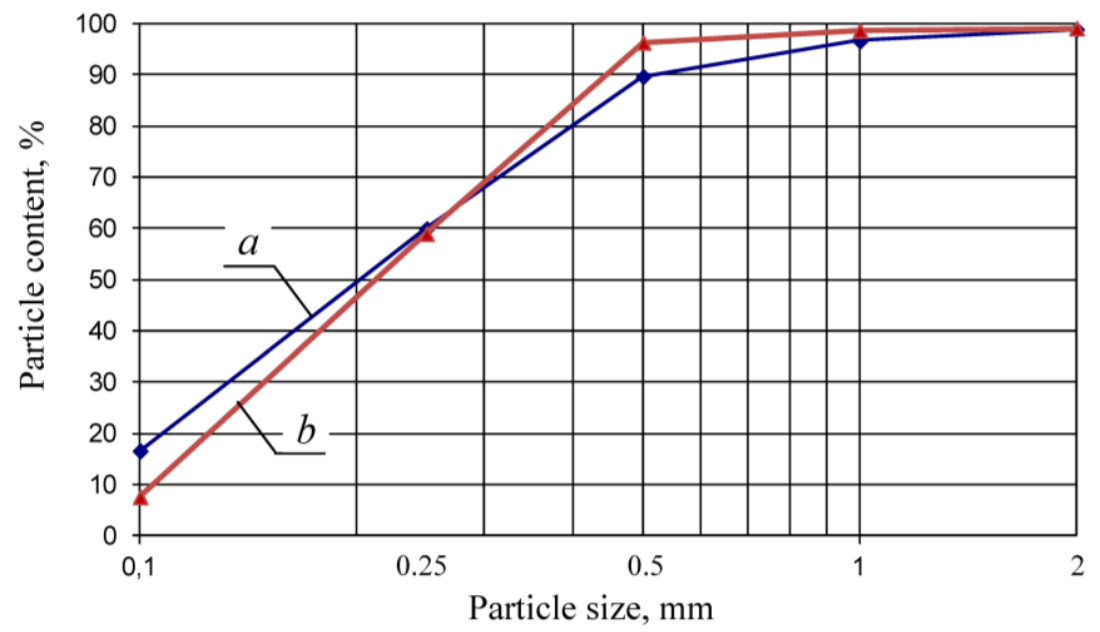

Fig.3. Average grain-size composition of materials: a) filling the space between crushed stone particles; b) drain backfilling sand. 
Water permeability of the materials was determined on the samples $50 \mathrm{~mm}$ high and 60 $\mathrm{cm}^{2}$ in cross section, with the head gradient 1,3 and 5. The test results are given in Figure 4.

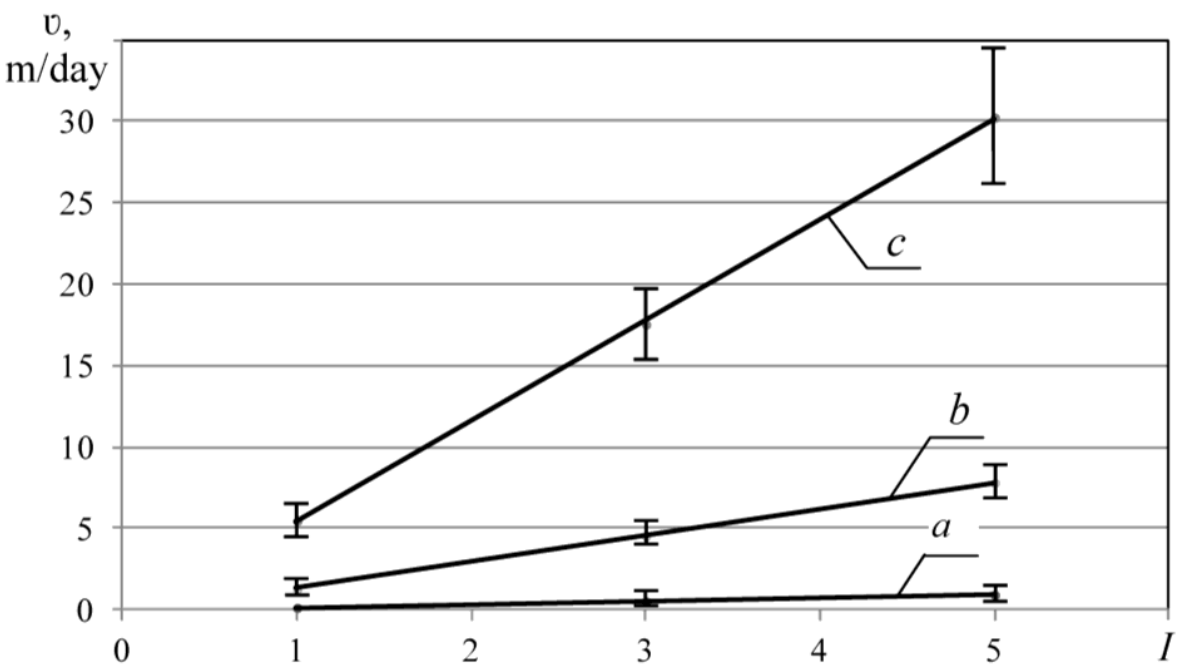

Fig.4. Filtration rate vs hydraulicgradient for samples: a - No.1, b - No.2, c - No.3-6.

The permeability factor at the top of stone cover turned out to be 4 to 5 times less than that of the backfilling material, and at the bottom of stone cover - 30 to 35 times less. The given values are two to three orders of magnitude below the permeability factor of crushed stone. The considerable reduction in water permeability of the stone cover is caused by sand and clayey particles and organic matter plugging the pores in the crushed stone.

\section{Laboratory experiments}

To evaluate the reliability of drains with geotextile filters, they were subjected to laboratory tests in filtration tubes $100 \mathrm{~mm}$ in diameter, $1.5 \mathrm{~m}$ long (Figure 5). Non-woven geotextile fabric with the density of $250 \mathrm{~g} / \mathrm{m} 3$ was used as filter. Layers of fine and coarse sand were used to simulate the drain backfilling and stone cover. Grain-size composition of sand is given in Table 1. Peat in the loading scheme shown in Figure 5 was of medium decomposition degree, and contained approx. 37 to $43 \%$ of particles above $0.25 \mathrm{~mm}$. A protective layer of gravel $50 \mathrm{~mm}$ thick was placed on top of sand and peat in the filtration tubes. The filtering fluid level in the tubes was adjusted to ensure approximately equal flow rates of the filtered fluid. 


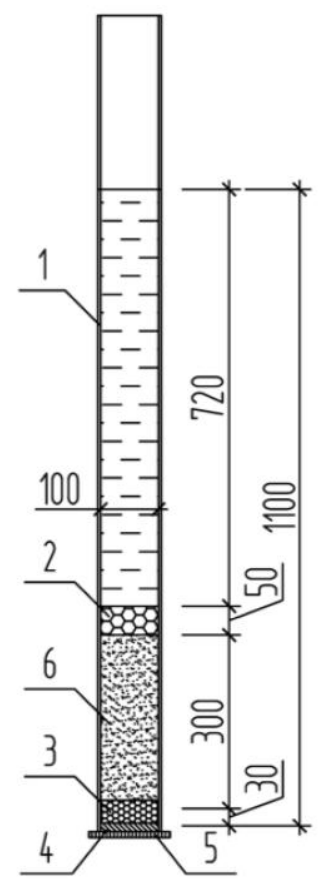

$a$

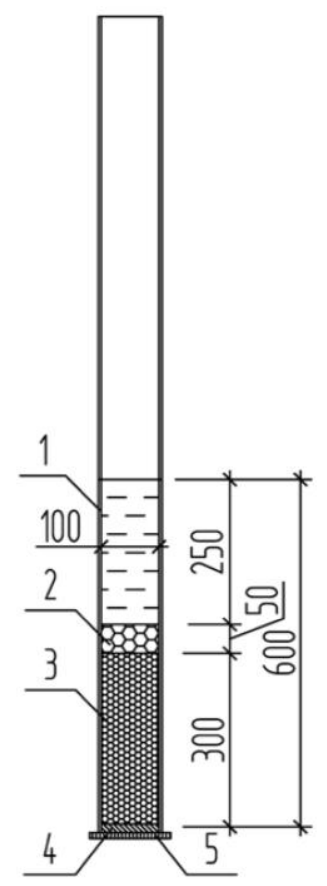

$b$

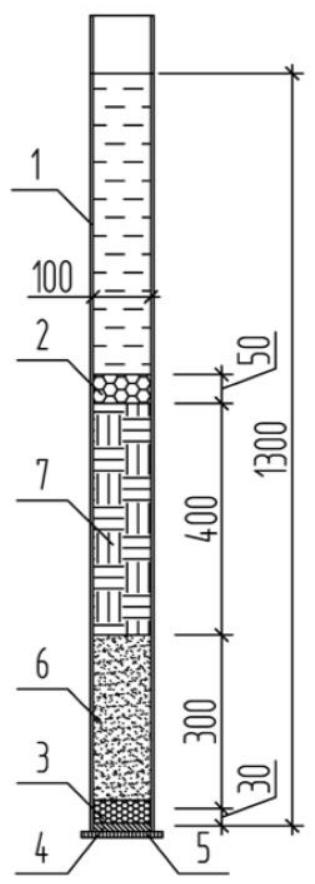

$c$

Fig.5. Filtration tube loading schemes: 1 - filtration tube, 2 - gravel, 3 - coarse sand; 4 - geotextile, 5 - perforated bottom, 6 - fine sand, 7 - peat.

Table 1. Grain-size composition of sands used in laboratory experiments.

\begin{tabular}{|c|c|c|c|c|c|c|c|}
\hline \multirow{2}{*}{ Soil } & \multicolumn{7}{|c|}{ Content of particles, \%, of size, $\mathrm{mm}$} \\
\cline { 2 - 8 } & $>5$ & $5-2$ & $2-1$ & $1-0.5$ & $0.5-0.25$ & $0.25-0.10$ & $<0.1$ \\
\hline Fine sand & 0 & 0.05 & 0.15 & 1.2 & 25.5 & 71.6 & 1.5 \\
\hline $\begin{array}{c}\text { Coarse } \\
\text { sand }\end{array}$ & 0 & 7.2 & 29.4 & 55.8 & 4.6 & 1.4 & 1.6 \\
\hline
\end{tabular}

Two types of tube bottoms were used: with a single hole and with continuous perforation, where the total holes area accounted for at least $40 \%$ of the tube area. The single hole simulated pipe wrapping with geotextile, and the perforated bottom simulated the placement of geotextile filter along the external outline of the stone cover (Figure 6). In the second case, an additional layer of gravel was laid between the bottom and the geotextile filter.

A suspension containing clayey particles or humus was used as filtering fluid. Clayey particles for suspension were obtained by powdering the local clay and adding this to water in the amount of 1-1.5 g/litre. Grain-size composition of this soil is given in Table 2 . Humus particles were washed away in the course of water filtration through the peat layer located above the sand. The water flow rate was 25 to $50 \mathrm{l} /$ day. The total duration of experiments was 15 days. 


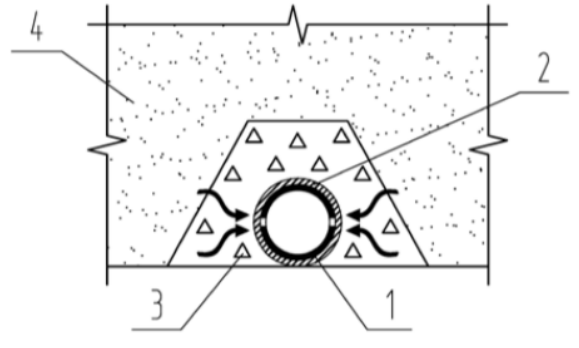

$a$

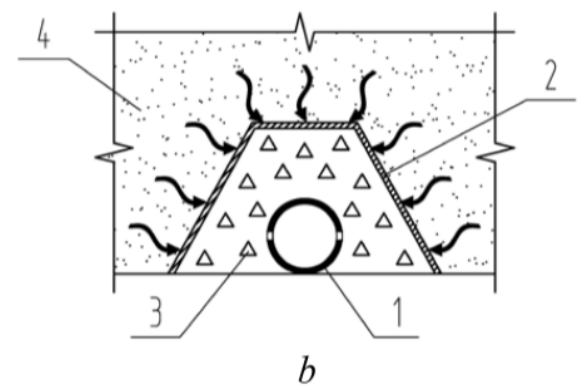

$b$

Fig.6. Direction of groundwater flow through geotextile wrapping:a - pipe wrapping with geotextile, $\mathrm{b}-$ geotextile located along the external outline of stone cover. Designations: 1 - drainpipe, 2 geotextile, 3 -stone cover, 4 - sand backfilling.

Table 2. Grain-size composition of clay.

\begin{tabular}{|c|c|c|c|c|c|c|c|c|}
\hline \multicolumn{10}{|c|}{ Content of particles, \%, of size, mm } \\
\hline$>1$ & $1-0,5$ & $0.5-0.25$ & $0.25-0.1$ & $0.1-0.05$ & $0.05-0.01$ & $0.01-0.005$ & $0.005-0.002$ & $<0.002$ \\
\hline 0.5 & 2.7 & 6.2 & 15.7 & 11.5 & 21.6 & 9.1 & 7.5 & 25.2 \\
\hline
\end{tabular}

After 15 days, water permeability of geotextile above the bottom with a single hole and backfilling of fine sand with clayey particles in the water flow virtually remained the same, and with back filling of course sand it decreased by 16,9 times. Humus particles decreased permeability of geotextileto 2.7 times.

In case of perforated bottom and suspension filtering through a fine sand layer, no clogging of geotextile filters was observed, whereas coarse sand caused the geotextile permeability to decrease by 9.4 times.

The absence of geotextile clogging in the case where suspension is flowing through fine sand layer can be explained by the fact that the particles capable of clogging geotextile are retained at the sand surface and in its pores.

The permeability factor values of sand layers before and after the experiment are given in Table 3.

Table 3. Water permeability of sand.

\begin{tabular}{|c|l|c|c|c|c|}
\hline \multirow{2}{*}{$\begin{array}{c}\text { Loading } \\
\text { scheme }\end{array}$} & \multirow{2}{*}{ Soil } & \multicolumn{4}{|c|}{ Permeability factor, m/day } \\
\cline { 3 - 6 } (Figure 3) & & \multicolumn{2}{|c|}{ before test } & \multicolumn{2}{c|}{ after test } \\
\cline { 3 - 6 } & & range & average & range & average \\
\hline $\mathrm{a}$ & Fine sand & $6.3-8.3$ & 7.2 & $1.7-3.6$ & 2.7 \\
\hline $\mathrm{b}$ & Coarse sand & $77.3-93.2$ & 85.0 & $11.8-19.5$ & 15.7 \\
\hline $\mathrm{c}$ & Fine sand & $7.5-8.9$ & 8.0 & $2.9-5.4$ & 4.4 \\
\hline
\end{tabular}

In the course of the laboratory experimentwe determined the size of particles at the outlet of filtration tubes, i.e. the particles that passed through the geotextile. Suspension was sampled after 1 minute, 1 day and 15 days after the test start. Grain-size composition was determined using a laser analyser Lasentec D600E, which employs the process of analysing the reflection of a focused beam in media with suspended particles. The measurement results are given in Table 4.

The experiments have shown that, in general, particles less than $0.15 \mathrm{~mm}$ are capable of penetrating geotextile filters. The greatest quantity of particles washed away from filtration tubes is accounted for by coarse sand backfilling. For example, with the "a" loading scheme, the amount of washed away particles reduced by 2 times after 1 day of filtration, and by 10 times after 15 days as compared their content at the test start, which is due to gradual clogging of pores in geotextile and sand. Low quantity of washed away particles with test schemes "a" and "c" is explained the small size of pores in fine sand. 
Table 4. Grain-size composition of particles that passedthrough geotextile filters.

\begin{tabular}{|c|c|c|c|c|c|}
\hline \multirow{2}{*}{$\begin{array}{c}\text { Loading } \\
\text { scheme } \\
\text { (Figure } \\
3 \text { ) } \\
\end{array}$} & \multirow{2}{*}{$\begin{array}{c}\text { Time } \\
\text { since } \\
\text { test start }\end{array}$} & \multicolumn{4}{|c|}{$\begin{array}{l}\text { Particle concentration, } \mathrm{g} / \text { litre, } \\
\text { depending on the size }(\mathrm{mm})\end{array}$} \\
\hline & & $0,05-0.15$ & $0.01-0.05$ & $0.005-0.01$ & $0.001-0.005$ \\
\hline \multirow{3}{*}{$\mathrm{a}$} & $1 \mathrm{~min}$. & $(4.3-6.4) \cdot 10^{-3}$ & $(7.8-9.2) \cdot 10^{-3}$ & $(6.3-10.5) \cdot 10^{-4}$ & $(1.6-2.3) \cdot 10^{-4}$ \\
\hline & 1 day & $(4.3-6.4) \cdot 10^{-3}$ & $(3.3-5.6) \cdot 10^{-3}$ & $(4.5-8.3) \cdot 10^{-4}$ & $(0.8-1.7) \cdot 10^{-4}$ \\
\hline & 15 days & $(2.1-4.3) \cdot 10^{-3}$ & $(1.9-4.2) \cdot 10^{-3}$ & $(0.4-1.0) \cdot 10^{-4}$ & $(0.08-0.23) \cdot 10^{-4}$ \\
\hline \multirow{3}{*}{ b } & $1 \mathrm{~min}$ & $(5.1-6.2) \cdot 10^{-2}$ & $(3.9-4.4) \cdot 10^{-1}$ & $(1.8-2.1) \cdot 10^{-2}$ & $(2.8-3.2) \cdot 10^{-3}$ \\
\hline & 1 day & $(2.5-3.0) \cdot 10^{-2}$ & $(2.1-2.3) \cdot 10^{-1}$ & $(0.75-0.87) \cdot 10^{-}$ & $(0.99-1.2) \cdot 10^{-3}$ \\
\hline & 15 days & $(0.64-0.85) \cdot 10^{-2}$ & $(0.25-0.28) \cdot 10^{-1}$ & $(0.13-0.15) \cdot 10^{-}$ & $(0.21-0.26) \cdot 10^{-3}$ \\
\hline \multirow{3}{*}{$\mathrm{c}$} & $1 \mathrm{~min}$ & $(8.5-17.0) \cdot 10^{-3}$ & $(7.8-9.6) \cdot 10^{-3}$ & $(1.7-5.4) \cdot 10^{-4}$ & $(2.3-7.7) \cdot 10^{-5}$ \\
\hline & 1 day & $(2.1-6.4) \cdot 10^{-3}$ & $(1.9-2.5) \cdot 10^{-3}$ & $(0.36-0.48) \cdot 10^{-}$ & $(2.1-3.8) \cdot 10^{-5}$ \\
\hline & 15 days & $(2.1-6.4) \cdot 10^{-3}$ & $(0.4-2.1) \cdot 10^{-3}$ & $(0.36-0.48) \cdot 10^{-}$ & $(0.38-0.57) \cdot 10^{-5}$ \\
\hline
\end{tabular}

\section{Conclusions}

Based on the conducted survey, the following conclusions can be drawn:

- traditional design solutions for drains laid over pile foundations facilitate the reduction of their water intake capacity due to accumulation of small mineral and organic particles in stone covers; for example, water permeability in the surveyed drainage system has reduced by up to 35 times after thirty years of operation;

- geotextile wrapping of drain pipes can lead to rapid reduction of their permeability where clayey particles and organic matter are present in the water flow;

- the preferred way of geotextile filter installation is along the external outline of the stone or gravel cover.

\section{References}

1. A.L.Nevzorov, A.V.Nikitin, Environmental Geoscience6, 561-566 (2003)

2. A.L.Nevzorov, A.V. Nikitin, A.V. Zarychevnych, A Cityon the Bog, 157 (2012)

3. V.M. Gerasimov, E.I. Nizhegorodcev, Systems, methods, technologies 4, 153-156 (2013)

4. A.V. Ishhenko, I. S. Lebedinec, Scientific Journal of Russian Scientific Research Institute of Land Improvement Problems1(13), 11 (2014)

5. A.I. Mitrahovich, I.Ch. Kaz'miruk, Improvement 1(73), 54-67 (2015)

6. A.I. Mitrahovich, Je.N. Shkutov, I.Ch. Kaz'miruk, V.V. Lebedev, Improvement 1(69), 46-56 (2013)

7. Ju.Ja.Tjumenev, M.Ju. Treshhalin, V.S. Mandron, Bulletin of the Association of Universities for tourism and service 3, 13-15 (2007)

8. A.I. Mitrahovich, V.T. Klimkov, I.Ch. Kaz'miruk, V.V. Lebedev, Improvement 1 (69), 57-65 (2013)

9. Je.N. Shkutov, A.I. Mitrahovich, V.P. Ivanov, V.M. Makoed, V.A. Derevjanko, N.M. Avramenko, Improvement 1 (71), 22-30 (2014)

10. V.T. Klimkov, I.Ch. Kaz'miruk, A.I. Mitrahovich, Improvement 1 (59), 36-43 (2008) 
11. K.V. Svalova,Mining information-analytical Bulletin 6, 391-396 (2013)

12. A.V. Ishhenko, P.V. Petrov,Scientific Journal of Russian Scientific Research Institute of Land Improvement Problems3(11), 8 (2013)

13. N.G. Pivovar, N.G. Bugaj, V.A. Rychko, Drainage with fiber filters, 211 (1980)

14. V. M. Zubec, A. E. Vakar, Operation of closed drainage systems, 136 (1989)

15. V.I. Zheljazko, A.I. Mitrahovich, I.Ch. Kaz'miruk, S.V. Nabzdorov, Improvement 1 (61), 54-67 (2009) 